\title{
El acceso y la difusión de los recursos bibliográficos e informativos en la Biblioteca Regional de Extremadura
}

\author{
María F. Sánchez Hernández \\ Universidad Rey Juan Carlos (España)
}

\section{Resumen}

Se analizan las actividades, funciones y servicios de la Biblioteca Regional de Extremadura desde que abrió sus puertas. Su objetivo prioritario es asegurar el acceso a la información a la sociedad extremeña, tanto con las fuentes documentales que en ella se conservan como las depositadas en otras bibliotecas. Para ello, la Biblioteca debe garantizar la recogida, conservación y difusión del patrimonio informativo de la comunidad en cualquier soporte, publicando una Bibliografía regional —en curso y retrospectiva_ y el Boletín del Depósito Legal de Extremadura. En segundo lugar, se relata la puesta en marcha de la organización del archivo fotográfico donado a la Biblioteca por El Periódico Extremadura.

Palabras clave: Bibliotecas regionales. Extremadura. Tratamiento técnico.

\section{Abstract}

Extremadura's Regional Library was conceived to be the technical and functional head of regional library system. It is the most important bibliographic and informative resource center in Extremadura, and its meeting point with the Spanish library system. The center is specifically devoted to research, collect, preserve and transmit Extremadura's bibliographic heritage. Special attention is devoted to the provision of the regional bibliography, the legal deposit bulletin and also to the photographic archive of El Periódico Extremadura.

Keywords: Regional library. Extremadura. Technical processing.

\section{Introducción}

El antiguo Hospital Militar de Badajoz alberga la Biblioteca de Extremadura y es la sede de la Facultad de Biblioteconomía y Documentación. En este edificio se ha efectuado una profunda rehabilitación, que ha contribuido a recuperar el entorno de la alcazaba de la ciudad. Un recinto histórico que tiene la calificación de Bien de Interés Cultural. 
El proyecto inicial fue modificado tras la aparición de importantes restos arqueológicos. Nos referimos a la antigua catedral de la ciudad - la primera que se erigió en Badajoz, alrededor del año 1230—; el mihrab de la mezquita, de uso privado del fundador de la ciudad, Ibn Marwan; o los restos de la posible sala del trono o salas de recepciones que este tuvo en el alcázar. Restos arqueológicos que están situados en la zona que ahora ocupa la Biblioteca y que se han integrado en la obra desde un punto de vista museístico para su visita.

Este proyecto se llevó a cabo por la Junta de Extremadura, colaborando en concreto la Consejería de Educación, Ciencia y Tecnología y la de Cultura. Se realizó como consecuencia de la voluntad política de establecer un sistema de interconexión de las distintas bibliotecas de la región y constituye, sin duda, un esfuerzo más para contribuir en el acercamiento de la cultura a los ciudadanos.

La Biblioteca de Extremadura tiene como objetivo prioritario garantizar el acceso a la información a la sociedad extremeña, no solo de los documentos que en ella se conservan, sino de aquellos localizados en otras bibliotecas. Para ello debe asegurar la recogida, conservación y difusión del patrimonio informativo de la comunidad en cualquiera de sus formas publicando la Bibliografía regional (en curso y retrospectivo) y el Boletín del Depósito Legal de Extremadura.

\section{Funciones principales de la Biblioteca}

La Biblioteca Regional de Extremadura tiene como funciones principales $a$ ) realizar el tratamiento documental de los tres ejemplares que ingresan en ella —de todo aquello que haya sido publicado en Extremadura y/o sobre Extremadura- y que esté sujeto a depósito legal en la forma que reglamentariamente se determine; $b$ ) elaborar y mantener el catálogo colectivo de todo tipo de publicaciones de las bibliotecas de Extremadura; $c$ ) ejercer como centro de control bibliográfico y central técnica de los trabajos bibliotecarios; d) posibilitar la interconexión con el Sistema Español de Bibliotecas y los demás sistemas autonómicos; $e$ ) fomentar el libro a través de las nuevas tecnologías; $f$ ) garantizar la recogida, conservación y difusión del patrimonio informativo de la comunidad en cualquier soporte, editando la Bibliografía regional —en curso y retrospectiva- y el Boletín del Depósito Legal de Extremadura.

\section{Secciones}

Fondo antiguo, raros y curiosos. Se trata de fondos extremeños o relacionados con Extremadura, manuscritos, incunables, raros y curiosos — los más valiosos de la Biblioteca- Las obras más destacadas se exponen en la sala del Tesoro Bibliográfico.

Fondos modernos. Ingresan a través del depósito legal o se adquieren por compra, canje o donación. 
Hemeroteca y fondos especiales. Aquí se encuentran las publicaciones periódicas (revistas, periódicos, boletines, etcétera) y los materiales especiales (CD, vídeos, carteles, grabados, fotografías...).

Referencia e información bibliográfica. Esta sección proporciona orientación al usuario, tanto de sus fondos documentales como de todos los disponibles en otras bibliotecas o puntos de información. Ofrece acceso a instrumentos de información —manuales y automatizados con recursos multimedia —. Esta sala dispone de ordenadores destinados a consultas y a la libre navegación por Internet; además se puede acceder al catálogo automatizado a través de los OPAC — Online Public Access Catalogue-.

Informática. Es la sección que se encarga de desarrollar la conexión de todo el sistema bibliotecario de Extremadura, así como conectar con otros sistemas mediante programas y aplicaciones informáticas necesarias para la elaboración de catálogos, bibliografías, boletines, etcétera.

Reprografía. El usuario dispone de aparatos reproductores de documentos, como fotocopiadoras y lector de microfilms — microfichas-, y acceso a la información localizada en los ordenadores.

\section{Servicios de la Biblioteca}

La Biblioteca ofrece diversos servicios, entre los que destacan los siguientes: a) gestión técnica de adquisición de fondos y labores de selección e identificación —utilizando el sistema Absys, bajo el formato MARC—; $b$ ) catalogación y clasificación de los fondos — también en Absys—; $c$ ) gestión de la colección: realización de inventarios, estudio de crecimiento, expurgos y selección de documentos para intercambio; $d$ ) atención al servicio de referencia: se realiza mediante consulta pública (OPAC cliente), con el manejo de fuentes de información, gestión de la biblioteca de referencia, etcétera; $e$ ) gestión del servicio de préstamo interbibliotecario; $f$ ) control estadístico de los servicios; $g$ ) cooperación en los proyectos dirigidos o con participación; $h$ ) participación en proyectos de cooperación interbibliotecaria; $i$ ) normalización y racionalización de los servicios y procesos.

\section{Tratamiento documental en Absys}

Hay varias funciones integradas en los módulos básicos del programa:

Catalogación y consulta. Esta función se utiliza en el proceso de descripción de fondos, indización, registro de ejemplares y recuperación.

Tesauro/autoridades. Ayuda de forma interactiva en el proceso de descripción.

Cliente Z39.50. Este módulo está integrado en las pantallas de catalogación.

Scire. $13: 1$ (en.-jun. 2007) 81-86. ISSN 1135-3716. 
Lectores y circulación. Permite el seguimiento para conocer la disponibilidad de los ejemplares de la biblioteca.

Adquisiciones. Es el módulo encargado de los pedidos de materiales y la gestión económica y presupuestaria.

Gestión de las publicaciones. Sirve para conocer sus ediciones.

Control de presupuestos. Gestiona las adquisiciones y las suscripciones a las publicaciones periódicas.

Mantenimiento. Permite acceder a las posibilidades avanzadas de parametrización de la biblioteca.

Administración desde el cliente. Realiza las funciones habituales de administración sin utilizar el servidor.

Impresos y estadísticas de cada módulo. Esta función es necesaria para el seguimiento preciso del funcionamiento de la biblioteca.

Consulta pública (OPAC cliente). Facilita a los usuarios consultar la información contenida en el catálogo, la disponibilidad de ejemplares — reservas, peticiones, etcétera- y el estado de la colección de publicaciones periódicas.

\section{Organización de las obras del depósito bibliográfico}

Estas obras se clasifican en dos grandes grupos.

El primero es el de las obras que pertenecen al fondo bibliográfico extremeño, y está compuesto por libros u obras en cualquier tipo de soporte realizados en Extremadura (independientemente de la nacionalidad) o que tratan de la región, y libros de autores extremeños.

En el segundo grupo se incluyen las obras que no son extremeñas ni tratan sobre Extremadura, pero que por su interés se conservan en la biblioteca; generalmente corresponden a un tema específico o bien engloban gran cantidad de materias (enciclopedias, diccionarios, etcétera), y están disponibles para los investigadores — sus usuarios potenciales-.

\section{Archivo fotográfico}

Fue donado por El Periódico Extremadura en el año 2003. Las primeras tareas llevadas a cabo para conocer este fondo han consistido en seleccionar, ordenar y clasificar el material gráfico de forma manual. El archivo está formado principalmente por imágenes, aunque algunos sobres contienen recortes de prensa, que de momento se han apartado para su posterior valoración y tratamiento documental. Contiene mayoritariamente fotografías en blanco y negro, y un número menor de fotografías en color y de diapositivas. 
Está subdividido en dos grandes apartados: el general, que abarca temáticas diversas no vinculadas a la región, y el específico, dedicado a todo lo acontecido en Extremadura.

Su clasificación, de momento, sigue siendo manual y corresponde a diferentes materias: $a$ ) de carácter general — se trata de temas relacionados con la universidad, deportes, ferias, exposiciones, elecciones, partidos políticos, etcétera-; $b$ ) de forma más concreta — son imágenes que se centran en una o varias comarcas extremeñas—, que a su vez se dividen temáticamente, por ejemplo, en fiestas patronales, costumbres, gastronomía, ayuntamientos, sucesos, agricultura, etcétera.

\section{Resultados y conclusiones}

Como hemos comprobado con este estudio, esta unidad de información ofrece, gracias a las técnicas empleadas en su gestión y organización, un acercamiento de la información de carácter científico, obras de referencia y otros materiales documentales a sus usuarios, facilitando asimismo el acceso informativo-bibliográfico sobre Extremadura, de forma manual o automatizada y en distintos soportes.

El personal a cargo de la Biblioteca Regional de Extremadura está formado por un director, un documentalista, un técnico de biblioteca, un técnico de administración, un auxiliar de administración, dos auxiliares de biblioteca, un técnico de informática, dos auxiliares de informática y dos ordenanzas. El número de usuarios asciende a 12312 según las estadísticas de 2003.

Para concluir este trabajo, en la tabla I podemos observar las cifras de fondos de cada apartado - datos facilitados por la Biblioteca y correspondientes a septiembre de 2004-.

\begin{tabular}{|l|l|}
\hline Fondos antiguos, raros y curiosos & 777 \\
\hline Fondos modernos & 14195 (catalogados) \\
& 10000 (sin catalogar) \\
\hline Hemeroteca y fondos especiales & 436 (títulos de publicaciones periódicas) \\
& 409 (documentos electrónicos, CD-ROM y DVD-ROM) \\
& 539 (fondos audiovisuales) \\
\hline Archivo fotográfico & 110000 (aproximadamente) \\
\hline
\end{tabular}

Tabla I. Fondos de la Biblioteca de Extremadura en septiembre de 2004.

\section{Referencias}

Amat i Noguera, Nuria (1992). La biblioteca: tratado general sobre su organización, técnicas y utilización. Barcelona: Scripta, 1992.

Biblioteca de Extremadura, Badajoz. http://www.unex.es/interzona/extremadura/ (200403-09).

Scire. $13: 1$ (en.-jun. 2007) 81-86. ISSN 1135-3716. 
Carrera Mancera, Carmen de la (2000). La biblioteca de Extremadura. // Boletín de la Anabad. 50 (jul.-dic. 2000) 3-4.

Carrión Gútiez, Manuel (1993). Manual de bibliotecas. Madrid; Salamanca: Fundación Germán Sánchez Ruipérez; Pirámide, 1993.

Gómez Hernández, José Antonio (1997). Biblioteconomía general y aplicada: conceptos básicos de gestión de bibliotecas. Murcia: Librero, 1997.

Ros García, José; López Yepes, José (1994). Políticas de información y documentación. Madrid: Síntesis, 1994. 